\title{
I like those glasses on you, but not in the mirror: Fluency, preference, and virtual mirrors
}

\author{
Hyejeung Cho ${ }^{\mathrm{a}, *}$, Norbert Schwarz ${ }^{\mathrm{b}}$ \\ ${ }^{\text {a } U n i v e r s i t y ~ o f ~ T e x a s ~ a t ~ S a n ~ A n t o n i o, ~ D e p a r t m e n t ~ o f ~ M a r k e t i n g, ~ O n e ~ U T S A ~ C i r c l e, ~ S a n ~ A n t o n i o, ~ T X ~ 78249-0638, ~ U S A ~}$ \\ ${ }^{\mathrm{b}}$ University of Michigan, Ann Arbor, MI 48106-1248, USA
}

Received 31 October 2009; revised 7 July 2010; accepted 11 July 2010

Available online 3 August 2010

\begin{abstract}
Consumers like the same accessories (eye glasses and earrings) more, and are more likely to recommend a purchase, when the accessories are displayed on a familiar other's regular image rather than mirror image. However, image format does not affect consumers' judgments when the other person is unfamiliar. These findings reflect differences in consumers' natural exposure history: we see others more often face-to-face than in the mirror, giving their regular image a fluency advantage; this advantage does not apply to unfamiliar others, whose image is disfluent in either presentation format. Theoretical and applied implications are discussed.
\end{abstract}

(C) 2010 Society for Consumer Psychology. Published by Elsevier Inc. All rights reserved.

Keywords: Virtual mirror; Fluency

Suppose your friend stands in front of a mirror and is trying on new eye glasses. She wants to hear your opinion. Would it make a difference if you stood next to her, watching her in the mirror, or if she turned around? In both cases, you would see the same glasses on the same face. However, you have seen your friend less frequently in a mirror than face-to-face, making her mirror image less familiar and less fluent to process. Fluent processing is generally experienced as hedonically pleasant and known to elicit more favorable aesthetic judgments (see Reber, Schwarz, \& Winkielman, 2004; Schwarz, 2004, for reviews). But in the present case, the glasses are always new - only your friend's face itself is likely to be less fluent when seen in the mirror. Would the mirror nevertheless influence your liking of her new glasses? Would the mirror have the same effect if a stranger asked you for your opinion?

Three decades ago, Mita, Dermer and Knight (1977) reported that people prefer their own mirror image over their own regular image, but their lover's regular image over his or her mirror image. This observation follows directly from the logic of Zajonc's (1968) mere exposure effect: while we see ourselves more often in the mirror than otherwise (privileging our mirror

\footnotetext{
* Correspondence author. Fax: +1 2104586335 .

E-mail address: hyejeung.cho@utsa.edu (H. Cho).
}

image), we rarely see others in the mirror (privileging their regular image). These effects were observed although participants found the regular and mirror images "almost indistinguishable" (Mita et al., 1977, p. 600) when presented side-by-side. Building on this observation, we test whether the differential fluency resulting from differential exposure histories influences perceivers' aesthetic response to products they have not seen before. For example, do novel eye glasses or jewelry "look better" when applied to a fluently rather than disfluently processed face? We address this research question in the context of a novel marketing tool, namely "virtual mirror" (or virtual presentation) technology, which allows consumers to virtually try on products by applying them to their own digital image or to explore what a gift would look like "on" the recipient.

\section{Virtual mirror technology}

A frequently noted disadvantage of online retailers is that consumers cannot directly experience products (e.g., Chiang \& Dholakia, 2003). To counter this disadvantage, the so-called virtual mirror technology allows consumers to create a virtual model by uploading a digital image of themselves, offering them the opportunity to see how a product would look "on them" when 
they cannot physically test or see the product (for examples, visit the websites of L'Oreal, Clairol, Matrix, and Eyeglasses.com). This technology also opens new opportunities for consumers who are looking for a gift. By uploading an image of the intended gift recipient to a retailer's website, the gift giver can assess how the gift would look "on" the recipient.

Such simulation technologies are not limited to online retailers; conventional stores can take advantage of them by inviting shoppers to snap a self-portrait at a virtual mirror kiosk in the store, allowing for more efficient initial product trials. Despite the potential of these technologies and their likely future use, neither virtual mirror technology itself nor its potential as a basic research tool have received much attention in consumer research. The present study contributes to an understanding of the psychological processes involved in evaluating products in a virtual mirror environment by exploring the role of consumers' fluency experiences; in doing so, it highlights natural variations in fluency that have received little attention in consumer research.

\section{Fluency, aesthetic experience, and consumer preference}

What makes a product aesthetically pleasing? One answer, supported by numerous findings in psychology and experimental aesthetics, holds that aesthetic pleasure is a function of processing fluency: any variable that increases the fluency with which an object can be processed also increases the perceiver's aesthetic pleasure (for reviews see Reber et al., 2004; Schwarz, 2004). Variables that facilitate fluent processing include variables that are the mainstay of experimental aesthetics, such as figural goodness, symmetry, and information density (for a review see Arnheim, 1974), as well as variables rarely considered of "aesthetic" relevance. The latter range from frequency of exposure, as documented in Zajonc's (1968) mere exposure effect, to contextual variables that facilitate processing of the target stimulus, such as visual (e.g., Reber, Winkielman, \& Schwarz, 1998) or semantic (e.g., Labroo, Dhar, \& Schwarz, 2008) primes. Fluent processing, in turn, is hedonically marked and experienced as pleasant (Winkielman, Schwarz, Fazendeiro, \& Reber, 2003). Using electromyography (EMG), Winkielman and Cacioppo (2001; Harmon-Jones \& Allen, 2001) observed that fluent processing is accompanied by increased activity over the region of the zygomaticus major ("smiling muscle"), which is indicative of a spontaneous positive affective response, which can also be captured in self-reports of current mood (Monahan, Murphy, \& Zajonc, 2000). This positive affective response mediates the impact of fluent processing on many evaluative judgments, including aesthetic assessments (Reber et al., 2004; Winkielman et al., 2003). Accordingly, fluency effects on aesthetic preference are attenuated or eliminated when the elicited affect is attributed to an unrelated source (Winkielman et al., 2003), consistent with the predictions of feelings-as-information theory (Schwarz \& Clore, 1983, 2007).

The variables reviewed above-from preceding primes to visual characteristics of the target and the frequency of previous exposure-share that they influence the fluency with which the target stimulus itself can be processed. In these cases, the perceiver's affective response is indeed elicited by the target stimulus, although not necessarily for the reason assumed by the perceiver, who would discount the subjective experience if she realized that it was facilitated by semantic primes, for example. However, perceivers are unlikely to notice such influences. As numerous studies in the feelings-as-information tradition demonstrate, they assume that any feeling they experience bears on whatever is in the focus of their attention-or why else would they experience it now, at this moment? Accordingly, incidental feelings frequently serve as information in evaluating unrelated targets, unless perceivers' attention is drawn to the source of the feeling (for a review see Schwarz \& Clore, 2007).

By the same token, perceivers may evaluate a target product on the basis of the affective response elicited by fluently processed context information. This is particularly likely when the context is relevant to the evaluation of the target, as is the case for virtual mirror technology, which has been developed to provide consumers with an opportunity to test how a product looks "on them" or "on" the intended recipient of a gift.

\section{The present research}

In the present study, we asked university students to evaluate the aesthetic appeal of eyeglasses and earrings shown on a virtual model. We predicted that participants would find a given product more aesthetically appealing when it is shown on a familiar person's regular image rather than mirror image. However, image format (regular or mirror) should exert no influence on participants' product evaluations when the person in the photo is unfamiliar, in which case neither format enjoys a fluency advantage.

\section{Method}

\section{Participants and design}

Eighty undergraduate students ( 37 males) participated in a 2 (Person familiarity: familiar vs. unfamiliar other) $\times 2$ (Image format: regular vs. mirror image) $\times 2$ (Product: eye glasses vs. earrings)-factorial experiment, with product as a withinparticipants replicate factor.

Because identical products may look differentially appealing on different faces, we used the same person (a female marketing instructor) as the "virtual model" in all conditions. Half of our participants were recruited from her undergraduate marketing class ("familiar other" condition), whereas the other half were recruited from another undergraduate marketing class ("unfamiliar other" condition). Within both conditions, participants were randomly assigned to either the virtual model's "regular" image or her "mirror" image.

\section{Materials and procedure}

Each participant evaluated two products (a pair of eyeglasses and a pair of earrings) applied to the virtual model's image. We prepared the regular photo image and mirror image using Adobe PhotoShop and applied products to these images using VirtualMakeOver. Fig. 1 shows an example of a person's regular image 

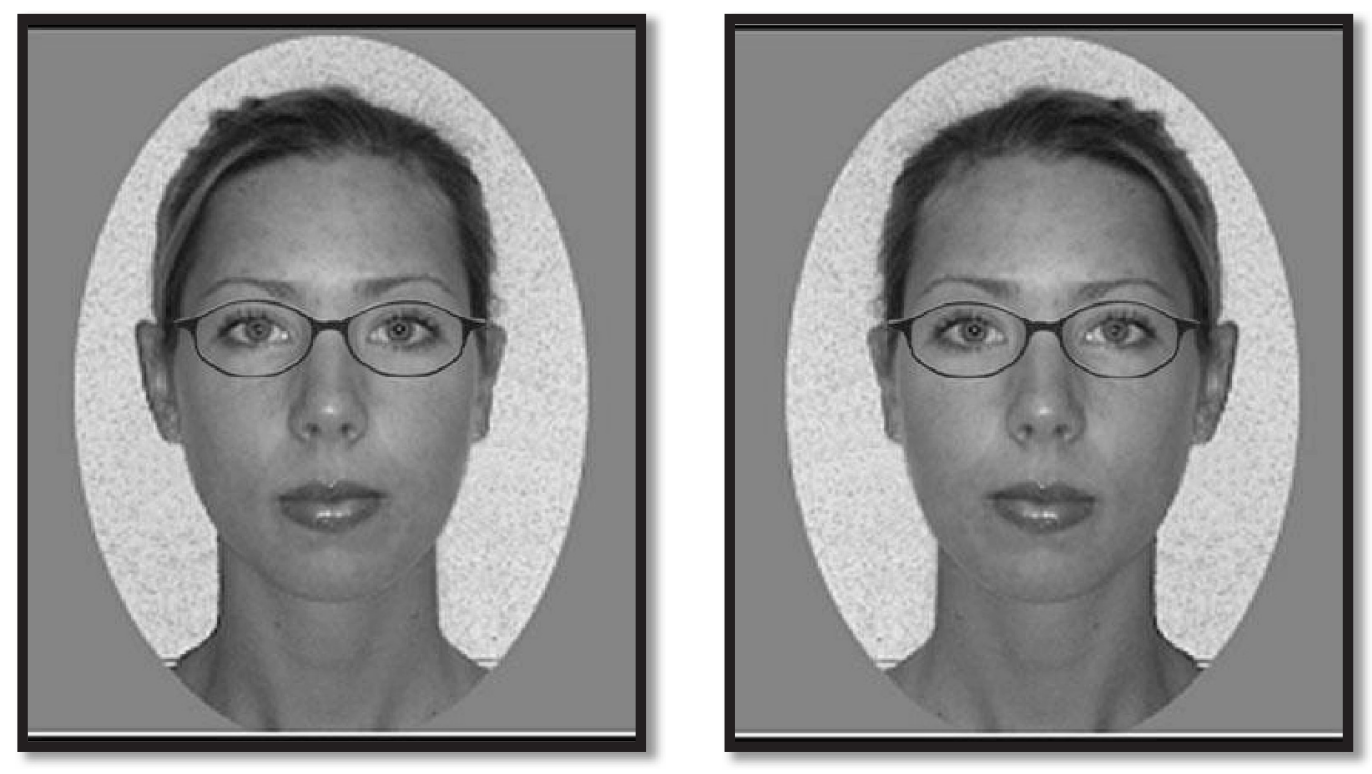

Fig. 1. Sample photos: eye glasses virtually applied to a person's regular (left) and mirror (right) image.

and mirror image, created by reversing the photo image to arrive at the equivalent of seeing the person in the mirror.

All participants read the following shopping scenario and instructions:

"This study is to learn about how consumers evaluate products in an online shopping place. Imagine that you are shopping for some personal accessory items for someone in an online shopping mall. To see if a product looks good on the person, ideally you would want to see different products "tried on" the person. When you shop online, you can use the person's digital photo and try various items on the photo to make a "how does it look on him/her?" judgment. To simulate this shopping scenario in the current study, we will present you with some virtual product trial photos using someone's photo. For each product trial photo, please think about how the product looks on the person in the photo and answer the questions that follow."

Participants then saw the model's first product trial photo on a computer screen, where she was wearing a pair of eye glasses; depending on the between-participants image format condition, the glasses were applied to her regular or mirror image. Participants then answered three questions, namely "How does the product look on her?" ( $1=$ not good at all; $7=$ very good); "In this hypothetical shopping scenario, how likely is it that you would consider buying/choosing this product for her?" and "In this shopping scenario, how likely is it that you would recommend her to buy/choose this product?" (1=not at all; $7=$ very likely). Subsequently, they saw the second product trial, which applied a pair of earrings to the same image.

Finally, participants reported if they knew the person in the photos (as a manipulation check) and whether they had noticed anything unusual about the photos presented to them. We also invited participants to speculate about the purpose of the study before they were fully debriefed and thanked.

\section{Results}

\section{Manipulation check}

Our manipulation check verified that all participants assigned to the familiar other condition knew the person in the photo, whereas none of the participants assigned to the unfamiliar other condition did. In addition, no participants indicated that they had noticed anything unusual about the virtual model's photos, other than the fact that she was wearing different products (glasses and earrings) in the two photos.

\section{Aesthetic appeal}

A 2 (Person familiarity: familiar vs. unfamiliar other) $\times 2$ (Image format: regular vs. mirror image) $\times 2$ (Product: eye glasses vs. earrings) ANOVA, with the last factor treated as a within-participants factor, revealed two statistically significant effects. First, a main effect of product indicated that participants rated the earrings $(M=4.38)$ more favorably than the eyeglasses $(M=3.33)$ regardless of person familiarity or image format; $F(1$, $76)=18.24, p<.01$. This is without theoretical interest and the product variable is not involved in any higher order interactions.

Second, and more important, a significant interaction of person familiarity and image format $(F(1,76)=5.45, p<.05)$ indicated that the regular vs. mirror image manipulation exerted a differential influence depending on the person familiarity. Fig. 2 shows this interaction. When the virtual model was their own marketing instructor, participants felt that the products "looked better" on her when they were presented on her regular image $(M=4.53)$ rather than her mirror image $(M=3.20) ; F(1$, $76)=8.51, p<.01$ for the contrast. The observed effect qualifies as large by Cohen's (1988) criteria, $d=.97$. In contrast, image format did not influence participants' product evaluations when the same model was unfamiliar $(M ' s=3.75$ vs. 3.93 for the regular and mirror image, respectively; $d=.12) ; F<1$ for the 


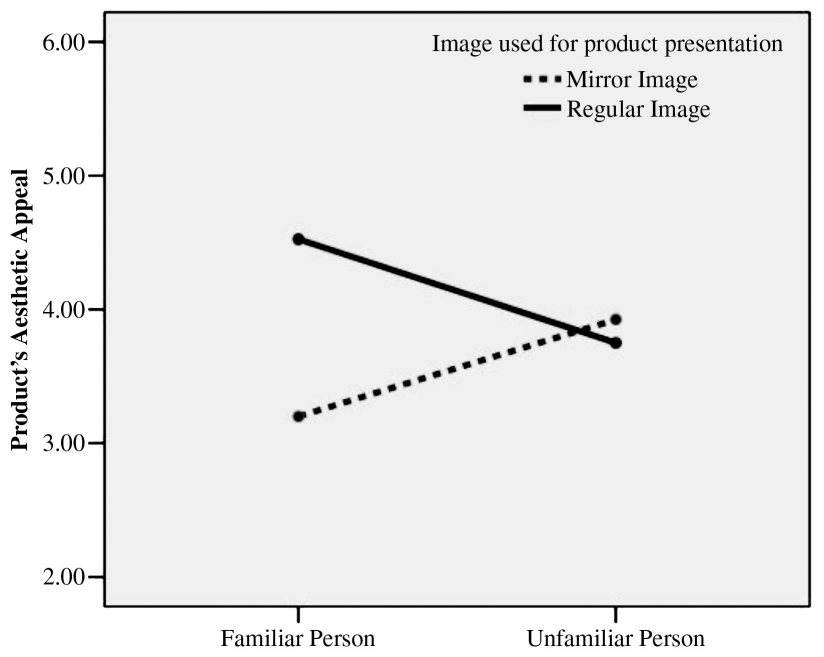

Fig. 2. Person familiarity $\times$ image format interaction for aesthetic appeal judgments.

contrast. This pattern supports our predictions and is not qualified by a higher order interaction; $F<1$.

\section{Purchase and recommendation intentions}

Participants' reported purchase and recommendation likelihoods were highly correlated ( $r$ 's $=.88$ and .90 for the eye glasses and the earrings, respectively) and averaged for further analysis. An ANOVA paralleling the above analyses again showed a main effect of product that is of little theoretical interest. Participants reported a higher purchase/recommendation likelihood for the earrings $(M=4.11)$ than the eyeglasses $(M=2.89) ; F(1,76)=23.38, p<.01$. More important, the previously observed interaction of person familiarity and presentation image format replicated on the purchase/recommendation measure, $F(1,76)=3.71, p<.06$. As expected, participants reported a higher likelihood of purchase and recommendation when the product was presented on the regular image $(M=4.10)$ rather than the mirror image $(M=2.83)$ of the familiar person; $F(1,76)=8.21, p<.01$ for the contrast. The size of this effect again qualifies as large, with Cohen's $d=.97$. However, image format did not influence participants' purchase/recommendation intentions when the same model was unfamiliar $(M$ 's $=3.58$ vs. 3.51 for the regular and mirror image, respectively; $d=.05) ; F<1$ for the contrast. This pattern supports our hypotheses and is not qualified by a higher order interaction; $F<1$.

\section{Replication}

A methodological caveat needs attention. Ideally, the instructors of two parallel sections of the same class would have agreed to serve as virtual models, allowing random assignment of students from the two sections to "familiar" vs. "unfamiliar other" conditions by crossing section and instructor. This could not be realized. Hence, images of one single instructor were presented to students of her own class vs. someone else's class to manipulate person familiarity. This has the advantage that the products are always shown on the same face, thus avoiding noise from differential person $\times$ product fit. However, it has the disadvantage that person familiarity is necessarily confounded with the class from which participants were drawn. To address this methodological issue, we conducted a conceptual replication in which all participants were recruited from the same class and the products were presented on images of their own instructor (familiar other) vs. a stranger (unfamiliar other). This experiment replicated the above interaction of person familiarity and image format. ${ }^{1}$

\section{Discussion}

In sum, participants found the same products more appealing, and reported a higher likelihood of purchasing or recommending them, when the products were applied to the regular image rather than the mirror image of a familiar other. With Cohen's $d$ 's $>.90$, the observed effects of image format were large. In contrast, image format did not influence participants' responses when the person was unfamiliar. Consistent with the general observation that people are sensitive to their feelings but insensitive to where their feelings come from (for a review see Schwarz \& Clore, 2007), participants mistook their response to the fluently processed face as their response to the (novel and previously unseen) accessories displayed on the face. Hence, they evaluated the same accessories more favorably when they were presented on their instructor's regular image rather than mirror image. This difference between regular and mirror image formats was not observed for participants who had never taken a class from the instructor, thus eliminating the fluency advantages resulting from previous exposure. ${ }^{2}$

These findings have theoretical as well as applied implications. First, previous research into fluency effects on aesthetic judgment manipulated the fluency of the target object itself, e.g., by presenting it with differential figure-ground contrast or by varying exposure frequency as reviewed by Reber et al. (2004) and Schwarz (2004). In contrast, the present research changed the fluency with which a context stimulus could be processed, namely the face to which the target product was applied. The target product itself was always novel. Nevertheless, the evaluation of the target product in its intended context showed a pronounced fluency effect. Second, the present work draws attention to naturalistic variations in processing fluency

\footnotetext{
1 Participants' evaluation of the aesthetic appeal of either product was not affected by image type ( $M$ 's $=2.95$ for regular and 3.00 for the mirror image) when the virtual model was an unfamiliar person; $F<1$ for the planned contrast. In contrast, image type influenced aesthetic appeal when the virtual model was familiar, as presented earlier. This results in a replication of the previously observed interaction of familiarity and presentation image, $F(1,76)=4.09$, $p<.05$. More details are available from the authors upon request.

${ }^{2}$ Using other unfamiliar stimuli (e.g., a novel landscape image A and its mirror image B), Pandelaere, Millet, \& Van den Bergh (2010) observed that people prefer the one to which they are first exposed over the one they encounter later, even when exposure frequency and duration are controlled for. This raises the possibility that order effects may also be observed with exposures to unfamiliar faces. Our experiments were not designed to detect order effects and are silent on this possibility.
} 
that result from differential exposure histories. The same objective variable (regular vs. mirror image) has differential effects depending on whether the image pertains to a familiar or unfamiliar other. Managerially, our observation highlights how the interplay between consumers' idiosyncratic exposure histories and marketers' choice of presentation formats in the use of the virtual mirror technology can influence product perceptions and purchase recommendations.

From a theoretical perspective, the fluency effects observed in our study - in which the response to the context serves as a basis for evaluating the embedded target - should be particularly likely when the nature of the task does not highlight the need to distinguish between target and context. This is typically the case when consumers consider the purchase of clothing and accessories, products that derive their value from how they look "on" the person who wears them. Note also that fashion items are usually purchased with a hedonic (experiential) consumption goal in mind, which further increases the likelihood that consumers consult their feelings during the decision process (for a review see Pham, 2004). In contrast, consumers are less likely to consult their feelings when they purchase a product with instrumental goals in mind. They may also be more attentive to target-context distinctions when the product's value is not tied to the context in which it is displayed. Future research may fruitfully explore the relative strength of fluency effects under such conditions, as well as their broader role in consumers' online experience outside of a purchase context (Joy, Sherry, Venkatesh, \& Deschenes, 2009).

To return to our opening question, would it make a difference if we saw our friend in the mirror or face-to-face while she is trying on new eye glasses? Yes, we would find her glasses more appealing face-to-face than in the mirror and would be more likely to recommend a purchase in the former than the latter case. Yet this difference in perspective would not affect our perception of the glasses tried on by the stranger standing next to her.

\section{References}

Arnheim, R. (1974). Art and visual perception: The new version. Berkeley: University of California Press.
Chiang, K., \& Dholakia, R. R. (2003). Factors driving consumer intention to shop online: An empirical investigation. Journal of Consumer Psychology, $13,177-183$

Cohen, J. (1988). Statistical power analysis for the behavioral sciences. Hillsdale, NJ: Lawrence Erlbaum Associates.

Harmon-Jones, E., \& Allen, J. J. B. (2001). The role of affect in the mere exposure effect: Evidence from psychophysiological and individual differences approaches. Personality and Social Psychology Bulletin, 27, 889-898.

Joy, A., Sherry, J., Venkatesh, A., \& Deschenes, J. (2009). Perceiving images and telling tales: A visual and verbal analysis of the meaning of the internet. Journal of Consumer Psychology, 19, 556-566.

Labroo, A. A., Dhar, R., \& Schwarz, N. (2008). Of frog wines and frowning watches: Semantic priming, perceptual fluency, and brand evaluation. Journal of Consumer Research, 34, 819-831.

Mita, T. H., Dermer, M., \& Knight, J. (1977). Reversed facial images and the mere-exposure hypothesis. Journal of Personality and Social Psychology, 35, 597-601.

Monahan, J. L., Murphy, S. T., \& Zajonc, R. B. (2000). Subliminal mere exposure: Specific, general, and diffuse effects. Psychological Science, 6 , $462-466$

Pandelaere, M., Millet, K., \& Van den Bergh, B. (2010). Madonna or Don McLean? The effect of order of exposure on relative liking. Journal of Consumer Psychology, 20, 442-451.

Pham, M. T. (2004). The logic of feeling. Journal of Consumer Psychology, 14, 360-369.

Reber, R., Schwarz, N., \& Winkielman, P. (2004). Processing fluency and aesthetic pleasure: Is beauty in the perceiver's processing experience? Personality and Social Psychology Review, 8, 364-382.

Reber, R., Winkielman, P., \& Schwarz, N. (1998). Effects of perceptual fluency on affective judgments. Psychological Science, 9, 45-48.

Schwarz, N. (2004). Metacognitive experiences in consumer judgment and decision making. Journal of Consumer Psychology, 14, 332-348.

Schwarz, N., \& Clore, G. L. (1983). Mood, misattribution, and judgments of well-being: Informative and directive functions of affective states. Journal of Personality and Social Psychology, 45, 513-523.

Schwarz, N., \& Clore, G. L. (2007). Feelings and phenomenal experiences. In A. Kruglanski, \& E. T. Higgins (Eds.), Social psychology: Handbook of basic principles (pp. 385-407)., 2nd ed. New York: Guilford.

Winkielman, P., \& Cacioppo, J. T. (2001). Mind at ease puts a smile on the face: Psychophysiological evidence that processing facilitation elicits positive affect. Journal of Personality and Social Psychology, 81, 989-1000.

Winkielman, P., Schwarz, N., Fazendeiro, T. A., \& Reber, R. (2003). The hedonic marking of processing fluency: Implications for evaluative judgment. In J. Musch, \& K. C. Klauer (Eds.), Psychology of evaluation: Affective processes in cognition and emotion (pp. 189-217). Mahwah: Lawrence Erlbaum Associates.

Zajonc, R. B. (1968). Attitudinal effects of mere exposure. Journal of Personality and Social Psychology, 9, 1-27. 